\title{
Maternal and Perinatal Outcomes Among Pregnancies Complicated by Isolated Oligohydramnios Compared with Normal Amniotic Fluid Index
}

\author{
Shrestha $\mathbf{R}^{1}$, Uprety DK ${ }^{1}$, Thakur $\mathbf{A}^{1}$ \\ ${ }^{1}$ Department of Obstetrics and Gynaecology, BPKIHS, Dharan, Nepal
}

Received: 23-Sep-2016; Accepted: 17-Dec-2016

Aims: The study was aimed to compare the maternal and perinatal outcomes among pregnancies with isolated oligohydramnios compared to normal amniotic fluid volume between $37-42$ weeks.

Methods: It was a prospective cohort study done among the singleton pregnancies between 37-42 weeks with isolated oligohydramnios taken as cases $(\mathrm{n}=100)$ and pregnancies with normal levels of amniotic fluid matched to cases by gestational age and parity in 2:1 ratio fulfilling the inclusion criteria were taken as controls $(n=200)$. Both the mother and baby were followed up till discharge for outcomes.

Results: Majority of the patients $(\mathrm{n}=300)$ were of age group 20-30 years $(79.0 \%)$. Most of them $(\mathrm{n}=300)$ were primigravida $(74.0 \%)$. The overall caesarean section rate was $24.66 \%(\mathrm{n}=300)$. In the oligohydramnios group, $43.0 \%$ had undergone induction of labour ( $p$ value $<0.05), 63.0 \%$ had undergone caesarean section ( $\mathrm{p}$ value $=0.001$ ) and the most common indication for caesarean section was non-reassuring NST $(44.44 \%)(p$ value $<0.05) .26 .0 \%$ babies had low birth weight, $12 \%$ had birth defects, $10.0 \%$ were small for gestational age $(p$ value $<0.05)$. There were significantly more ICU admission $(13.0 \%$ vs $3.5 \%)$, early neonatal death $(6.0 \%$ vs $1.5 \%)$, fetal distress $(6.0 \%$ vs $1.5 \%)$ in the oligohydramnios compared to control group ( $p$ value $<0.05$ ).

Conclusions: Patients with oligohydramnios have increased labour induction, increased operative interferences and increased neonatal mortality and morbidity compared to patients with normal fluid volume.

Keywords: amniotic fluid index, caesarean section, non stress test, oligohydramnios

\section{INTRODUCTION}

Oligohydramnios, as defined by amniotic fluid index less than $5 \mathrm{~cm}$, has been associated with poor maternal and fetal outcomes. Oligohydramnios occurs in about $1-5 \%$ of pregnancies at term. Oligohydramnios is associated with increased pregnancy complications, increased risk of labour induction and caesarean delivery, fetal deformities, growth restriction, fetal distress and meconium stained liquor, perinatal mortality, low Apgar score, low birth weight and increased ICU admission. ${ }^{1}$ Oligohydramnios poses challenge to obstetrician, when diagnosed before term. About $12 \%$ of women whose pregnancies continue for a week beyond expected date of delivery; develop oligohydramnios due to declining placental function. Every case of oligohydramnios needs careful antenatal evaluation, continuous intrapartum fetal monitoring and good neonatal care for better perinatal

\section{CORRESPONDENCE}

Dr. Ramesh Shrestha

Assistant Professor, Department of Obstetrics and Gynaecology

BPKIHS, Dharan, Sunsari, Nepal

Phone Number:- 9842352484

E mail address:- stharamesh007@gmail.com outcome. ${ }^{2}$ Because adverse outcomes occur in highrisk pregnancies complicated by oligohydramnios, it commonly prompts labour induction for delivery as the standard management. Amniotic fluid volume is a predictor of the fetal tolerance of labour with increased incidence of cord compression leading to variable decelerations and fetal distress in oligohydramnios. ${ }^{3}$ Many consider induction of labour nowadays even with an isolated finding of a so-called "border-line" amniotic fluid volume $(5-8 \mathrm{~cm}) .{ }^{1}$ Ultrasound is a non invasive procedure ideal for evaluation of amniotic fluid volume ${ }^{4}$. The most widely used method is the amniotic fluid index, proposed by Phelan et al. ${ }^{5}$ It is calculated by adding the depth in centimeters of the largest vertical pocket in each of four uterine quadrants. The normal AFI is $8-18 \mathrm{~cm}$, borderline oligohydramnios is $5-8 \mathrm{~cm}$, oligohydramnios is $<5$ $\mathrm{cm}$, borderline high is $18-25 \mathrm{~cm}$ and high is $>25 \mathrm{~cm}$.

\section{METHODS}

This was a prospective case control study done over 12 months from march 2012-february 2013 AD. It was done in the antenatal ward of the department of obstetrics and gynaecology, BP Koirala Institute 
of Health Sciences, Dharan. The study was done only after approval by Institutional Ethical Review Board. For sample size calculation, all the pregnant patients who met the inclusion criteria during study period were taken as cases $(n=100)$ based on hospital record of previous year. For each case, two pregnant patients matched by gestational age and parity with normal liquor volume and meeting the inclusion criteria were taken as controls $(\mathrm{n}=200)$. The inclusion criteria were singleton pregnancies of 37-42 weeks gestation and isolated oligohydramnios $(\mathrm{AFI}<8 \mathrm{~cm})$. The exclusion criteria were pregnancy of $<37$ weeks and $>42$ weeks gestation, hypertension complicating pregnancy, uncertain pregnancy dating, placental abruption, placenta previa, prelabour rupture of membrane, congenital fetal anomalies, multifetal pregnancy, intrauterine fetal death, malposition and malpresentation. The cases and controls were enrolled in the study based on the ultrasound done within one week from admission $(\mathrm{AFI}<8 \mathrm{~cm})$ and within two weeks from admission (AFI $=8-18 \mathrm{~cm}$ ) respectively. Cases and controls were enrolled before onset of labour or during early labour. Written consent was taken before enrolling the patients. At admission, detailed history, general physical examination, abdominal examination and pelvic examination were done. Non stress test was done after admission for fetal assessment. Patient were managed according to the standard management protocol followed in the hospital after explaining the maternal and fetal prognosis. Both the mother and baby were followed up till discharge after delivery for outcomes.

The data were collected and entered in Microsoft Excel software and analysis done using SPSS software version 17. Pearson Chi-square test was used for comparison of data and difference was considered significant when $P$ value was less than 0.05 .

\section{RESULTS}

Majority of the patients $(79.0 \%, \mathrm{n}=237)$ were of age group20-30 years. $74.0 \%$ of them $(\mathrm{n}=222)$ were primigravida and $77.66 \%(\mathrm{n}=233)$ were nullipara (Table 1).

\begin{tabular}{|llll|}
\hline Characteristics & $\begin{array}{l}\text { Oligohy } \\
\text { dramnios } \\
\text { group }(\mathrm{n}=100)\end{array}$ & $\begin{array}{l}\text { Normal } \\
\text { AFI } \\
\text { group } \\
(\mathrm{n}=200)\end{array}$ & Total \\
\hline $\begin{array}{l}\text { Age of the patients } \\
<20 \text { years }\end{array} 14$ & 29 & $43(14.3 \%)$ \\
20-30 years & 80 & 157 & $237(79.0 \%)$ \\
$>30$ years & 6 & 1443 & $20(6.7 \%)$ \\
\hline
\end{tabular}

\begin{tabular}{|c|c|c|c|}
\hline \multicolumn{4}{|c|}{ Number of visits } \\
\hline Booked & 41 & 87 & $128(42.67 \%)$ \\
\hline Unbooked & 59 & 113 & $172(57.33 \%)$ \\
\hline \multicolumn{4}{|c|}{ Gestational age } \\
\hline $37-40$ weeks & 47 & 98 & $145(48.3 \%)$ \\
\hline 40-42 weeks & 53 & 102 & $155(51.7 \%)$ \\
\hline \multicolumn{4}{|c|}{ Number of gravida } \\
\hline 1stgravid & 74 & 148 & $222(74.0 \%)$ \\
\hline 2ndgravid & 17 & 34 & $51(17.0 \%)$ \\
\hline 03rdgravida & 9 & 18 & $27(9.0 \%)$ \\
\hline \multicolumn{4}{|c|}{ Number of parity } \\
\hline Nullipara & 77 & 156 & $233(77.66 \%)$ \\
\hline Primipara & 17 & 30 & $47(15.66 \%)$ \\
\hline$\square 2$ para & 6 & 14 & $20(6.66 \%)$ \\
\hline
\end{tabular}

Majority of the patients in the oligohydramnios group had symphysio-fundal height $(36.0 \%$ vs $5.0 \%)$ and abdominal girth $(24.0 \%$ vs $4.5 \%)$ smaller than the gestation compared to normal AFI group which was significant (Table 2).

Table 2. Distribution of study population based on the symphysio-fundal height and abdominal girth

\begin{tabular}{|llll|}
\hline Characteristics & $\begin{array}{l}\text { Oligohy } \\
\text { dramnios } \\
\text { group }(\mathrm{n}=100)\end{array}$ & $\begin{array}{l}\text { Normal } \\
\text { AFI group } \\
(\mathrm{n}=200)\end{array}$ & $\mathrm{P}$ value \\
\hline $\begin{array}{l}\text { Symphysio- } \\
\text { fundal height }\end{array}$ & & & $\mathrm{p}$ value $<0.05$ \\
$\begin{array}{l}\text { Corresponds } \\
\text { with } \\
\text { gestational }\end{array}$ & $64(64.0 \%)$ & $190(95.0 \%)$ & \\
age & & & \\
$\begin{array}{l}\text { Smaller than } \\
\text { gestational }\end{array}$ & $36(36.0 \%)$ & $10(5.0 \%)$ & \\
age $>2 \mathrm{~cm}$ & & & \\
$\begin{array}{l}\text { Abdominal } \\
\text { girth }\end{array}$ & & & \\
$\begin{array}{l}\text { Correspond } \\
\text { with } \\
\text { gestational }\end{array}$ & $76(76.0 \%)$ & $191(95.5 \%)$ & \\
age & & & \\
$\begin{array}{l}\text { Smaller than } \\
\text { gestational }\end{array}$ & $24(24.0 \%)$ & $9(4.5 \%)$ & \\
age $>2$ cm & & & \\
\hline
\end{tabular}

74 patients had undergone caesarean section accounting for the overall caesarean section rate of $24.66 \%$. $63.0 \%(n=63)$ in the oligohydramnios and $5.5 \%(n=11)$ in the normal AFI group had undergone caesarean section which was significant. Similarly; $43.0 \%(n=43)$ of the patients in the oligohydramnios and $23.5 \%(n=47)$ in the normal AFI group had undergone induction of labour which was also significant (Table 3). 
Table 3. Maternal outcomes based on different variables

\begin{tabular}{|c|c|c|c|}
\hline Characteristics & $\begin{array}{l}\text { Oligohy } \\
\text { dramnios } \\
\text { group }(n=100)\end{array}$ & $\begin{array}{l}\text { Normal } \\
\text { AFI group } \\
(\mathrm{n}=200)\end{array}$ & $P$ value \\
\hline $\begin{array}{l}\text { Onset of } \\
\text { labour }\end{array}$ & & & $\mathrm{p}$ value $<0.05$ \\
\hline $\begin{array}{l}\text { Spontaneous } \\
\text { onset of } \\
\text { labour }\end{array}$ & $39(39.0 \%)$ & $153(76.5 \%)$ & \\
\hline $\begin{array}{l}\text { Induction of } \\
\text { labour }\end{array}$ & $37(37.0 \%)$ & $47(23.5 \%)$ & \\
\hline $\begin{array}{l}\text { LSCS at } \\
\text { admission }\end{array}$ & $24(24.0 \%)$ & $0(0 \%)$ & \\
\hline $\begin{array}{l}\text { Mode of } \\
\text { delivery }\end{array}$ & & & $\mathrm{p}$ value $<0.05$ \\
\hline $\begin{array}{l}\text { Spontaneous } \\
\text { vaginal } \\
\text { delivery }\end{array}$ & $34(34.0 \%)$ & $171(85.5 \%)$ & \\
\hline $\begin{array}{l}\text { Instrumental } \\
\text { vaginal } \\
\text { delivery }\end{array}$ & $3(3.0 \%)$ & $18(9.0 \%)$ & \\
\hline $\begin{array}{l}\text { Caesarean } \\
\text { section }\end{array}$ & $63(63.0 \%)$ & $11(5.5 \%)$ & \\
\hline
\end{tabular}

Majority of the patients in the oligohydramnios group $(63.0 \%, \mathrm{n}=63)$ had undergone caesarean section for non-reassuring NST $(44.44 \%, n=28)$. But the most common indication in the normal AFI group was meconium stained liquor $(36.36 \%, \mathrm{n}=4)$ followed by non-reassuring NST $(27.27 \%, \mathrm{n}=3)$ and it was significant (Table 4).

Table 5. Neonatal outcomes based on different variables

\begin{tabular}{|c|c|c|c|c|}
\hline Variables & Oligohy dramnios group & $\begin{array}{l}\text { Normal } \\
\text { AFI group }\end{array}$ & Total & $P$ value \\
\hline Birth weight & & & & $\mathrm{p}$ value $<0.05$ \\
\hline$<2500$ gms & $26(26.0 \%)$ & $17(8.5 \%)$ & $43(14.33 \%)$ & \\
\hline $2500-4000 \mathrm{gms}$ & $74(74.0 \%)$ & $180(90.0 \%)$ & $254(84.66 \%)$ & \\
\hline$>4000$ gms & 0 & $3(1.5 \%)$ & $3(1.5 \%)$ & \\
\hline 5 minute APGAR score & $16(16 \%)$ & $20(10.0 \%)$ & $36(12.0 \%)$ & $\mathrm{p}$ value $=0.18$ \\
\hline Birth defects & & & & $\mathrm{p}$ value $<0.05$ \\
\hline Club foot & $10(10.0 \%)$ & 0 & $10(3.33 \%)$ & \\
\hline Pulmonary hypoplasia & $1(1.0 \%)$ & 0 & $1(0.33 \%)$ & \\
\hline Both & $1(1.0 \%)$ & 0 & $1(0.33 \%)$ & \\
\hline Small for gestational age & $10(10.0 \%)$ & 0 & $10(3.33 \%)$ & $\mathrm{p}$ value $<0.05$ \\
\hline ICU admission & $13(13.0 \%)$ & $7(3.5 \%)$ & $20(6.66 \%)$ & $\mathrm{p}$ value $<0.05$ \\
\hline Early neonatal death & $\mathrm{p}$ value $<0.05$ & $3(1.5 \%)$ & $9(3.0 \%)$ & $\mathrm{p}$ value $<0.05$ \\
\hline Ventilatory support & $\mathrm{p}$ value $<0.05$ & $3(1.5 \%)$ & $9(3.0 \%)$ & $\mathrm{p}$ value $<0.05$ \\
\hline Neonatal hyperbilirubinemia & $\mathrm{p}$ value $<0.05$ & $3(1.5 \%)$ & $9(3.0 \%)$ & $\mathrm{p}$ value $<0.05$ \\
\hline
\end{tabular}

\section{DISCUSSION}

In the present study, $79.0 \%(n=237)$ of the total patients were of age group $20-30$ years. $74.0 \%(n=74)$ and $57.33 \%(\mathrm{n}=172)$ patients were primigravida and unbooked respectively which is in consistent with the
Table 4. Distribution of study population based on the indications of caesarean section

\begin{tabular}{|llll|}
\hline $\begin{array}{l}\text { Indications of } \\
\text { LSCS }\end{array}$ & $\begin{array}{l}\text { Oligohy } \\
\text { dramnios } \\
\text { group }\end{array}$ & $\begin{array}{l}\text { Normal } \\
\text { AFI group }\end{array}$ & P value \\
\hline $\begin{array}{l}\text { Non- } \\
\text { reassuring } \\
\text { NST }\end{array}$ & $28(44.44 \%)$ & $3(27.27 \%)$ & p value $<0.05$ \\
$\begin{array}{l}\text { Failed } \\
\text { induction }\end{array}$ & $14(22.22 \%)$ & $1(9.09 \%)$ & \\
$\begin{array}{l}\text { Fetal } \\
\text { bradycardia }\end{array}$ & $11(17.46 \%)$ & $1(9.09 \%)$ & \\
$\begin{array}{l}\text { Meconium } \\
\text { stained liquor }\end{array}$ & $7(11.11 \%)$ & $4(36.36 \%)$ & \\
$\begin{array}{l}\text { Others } \\
\text { Total }\end{array}$ & $3(4.77 \%)$ & $2(18.18 \%)$ & \\
\hline
\end{tabular}

$26.0 \% \quad(n=26)$ of the babies delivered in the oligohydramnios group and $8.5 \%(\mathrm{n}=17)$ in the normal AFI group had low birth weight $(<2500$ grams). In the oligohydramnios group, $12.0 \%(n=12)$ babies had birth defects, $10.0 \%(\mathrm{n}=10)$ were small for gestational age ( $p$ value $<0.05)$. There were significantly more neonatal ICU admission (13.0\% vs $3.5 \%)$, early neonatal death $(6.0 \%$ vs $1.5 \%)$, need of ventilator support $(6.0 \%$ vs $1.5 \%)$ and neonatal hyperbilirubinemia $(6.0 \%$ vs $1.5 \%)$ among babies delivered in the oligohydramnios group compared to normal AFI group (Table 5). study by Bangal VB et al. ${ }^{2}$ The present study showed $77.66 \%(n=233)$ patients with oligohydramnios were nulliparous and the rate of neonatal ICU admission among babies born to oligohydramnios mothers was $13.0 \%(n=13)$ similar in a study by Garmel et 
$\mathrm{al}^{6}$ in which $67.0 \%$ women with oligohydramnios were nullipara and rate of neonatal Intensive Care Unit admission at birth was $18.5 \%$. The present study showed an increased caesarean section rate of $63.0 \%(n=63)$ in the oligohydramnios group similar in a study by Conway $^{7}$ and the increased caesarean delivery was attributed to non-reassuring fetal surveillance $(44.44 \%, \mathrm{n}=28)$ which is in contrast to the study by Conway as it was attributed to induction process.

In the present study, induction of labour was done in $37.0 \%(\mathrm{n}=37)$ patients with oligohydramnios out of which $37.8 \%(n=14)$ were delivered by caesarean section for failed induction and there were $6.0 \%$ $(n=6)$ babies requiring ventilator support due to respiratory distress and $6.0 \%(n=6)$ neonatal deaths. There was $17.17 \%$ increase in non-reassuring fetal heart rate patterns requiring caesarean section in oligohydramnios groups compared with normal AFI groups which is similar to the study by Casey et $\mathrm{al}^{8}$ in which he reported that induction of labour was done in $42.0 \%$ out of which $32.0 \%$ were delivered by caesarean section. He also found respiratory distress in $3.4 \%$ of neonates at birth and $25.0 \%$ increase in non-reassuring fetal heart rate patterns in cases of oligohydramnios compared with normal controls. The result of the present study is also consistent with the study done by Chauhan et $\mathrm{al}^{9}$ in which they concluded that AFI less than $5 \mathrm{~cm}$ was associated with increased risk of caesarean section for fetal distress and low Apgar score at 5 minutes. Chauhan et al ${ }^{9}$ and Yousseff et $\mathrm{al}^{10}$ reported that when amniotic fluid index was less than $5 \mathrm{~cm}$, the incidence of meconium staining was increased but in the present study, the incidence of meconium staining requiring caesarean section was decreased among oligohydramnios compared to normal $(11.11 \%$ vs $36.36 \%)$. Also the present study showed babies born with low birth weight $(26.0 \%)$, birth defects $(12.0 \%)$ and small for gestational age $(10.0 \%)$ were significantly higher in the oligohydramnios group. This is consistent with the studies by Zhang et $\mathrm{al}^{11}$, Chate $\mathrm{P}$ et $\mathrm{al}^{12}$, Bangal VB et $\mathrm{al}^{2}$, Morris $\mathrm{J} \mathrm{M}$ et $\mathrm{al}^{13}$, Shumway J B et $\mathrm{al}^{14}$, Randeniya $\mathrm{C}$ et $\mathrm{al}^{15}$, Sarno et $\mathrm{al}^{16}$, Golan et $\mathrm{al}^{17}$ and Desai et $\mathrm{al}^{18}$ in which there were increased chances of intrapartum fetal heart rate decelerations resulting in increased rate of caesarean section, low APGAR score at 5 minute, birth weight $<2.5 \mathrm{~kg}$, admission to Neonatal Intensive Care Unit, congenital anomalies
\& neonatal mortality. Consistent with the present study, Voxman et $\mathrm{al}^{3}$ observed that women with oligohydramnios were significantly more likely to have abnormal fetal heart rate tracings $(14.9 \%$ vs $5.3 \%$; p 0.005$)$ and increased rate of caesarean section for fetal distress $(9.7 \%$ vs $5.0 \% ; \mathrm{p}=0.06)$ as compared to women with normal amniotic fluid index. Baron et $\mathrm{al}^{19}$ have reported a $50.0 \%$ increase in variable decelerations during labour and a sevenfold increased caesarean section rate in women with oligohydramnios. Similarly, Locatelli et al ${ }^{20}$ reported that rate of caesarean delivery for non-reassuring fetal testing $(8.2 \%$ vs. $3.9 \%, \mathrm{p}<0.001)$ and rate of neonates with birth weight $<10$ th percentile $(13.2 \%$ vs. $5.5 \%, \mathrm{p}<0.001)$ were significantly higher in the amniotic fluid index $\leq 5 \mathrm{~cm}$ group compared with the amniotic fluid index $>5 \mathrm{~cm}$.

In the present study, 39.0\% $(\mathrm{n}=39)$ had spontaneous onset of labour, $37.0 \%(\mathrm{n}=37)$ had induction of labour, $37.0 \%(\mathrm{n}=37)$ women had vaginal delivery and $63.0 \%(n=63)$ had caesarean section out of which $44.44 \%$ ( $n=28)$ had non-reassuring fetal heart rate abnormalities in the oligohydramnios group. This is in consistent with a study by Jandial Charu et $\mathrm{al}^{1}$ in which labour was spontaneous in $28.0 \%$, induced in $58.0 \%$ women, $44.0 \%$ had normal vaginal delivery and $56.0 \%$ had caesarean section out of which $42.0 \%$ had fetal distress. Similar to the present study, Ahmad $\mathrm{H}$ et $\mathrm{al}^{21}$ reported rate of induction of labour and caesarean delivery as high as $63.0 \%$ and $42.0 \%$ respectively in patients with isolated oligohydramnios compared to $14.0 \%$ and $18.0 \%$ respectively in the unexposed group $(\mathrm{p}<0.001)$.

The results of the present study was also consistent with Chhabra $\mathrm{S}$ et $\mathrm{al}^{22}$ which showed pulmonary hypoplasia in $1-2 \%$ of newborns and compression limb deformities in $2.4 \%$ babies of retrospective cases and $3.4 \%$ of prospective cases with severe oligohydramnios. Similarly, Shumway JB et $\mathrm{al}^{17}$ reported quite higher incidence of pulmonary hypoplasia $(18.0 \%)$ and similar incidence of skeletal deformities $(3.0 \%)$ compared to the present study. Similarly, Rotschild et $\mathrm{al}^{23}$ found pulmonary hypoplasia in $1-2 \%$ of newborns born with severe oligohydramnios. In the present study, fetus with small for gestational age was found in $10 \%(n=10)$ of the cases with oligohydramnios and none in normal AFI group. Similarly, Shenker et $\mathrm{al}^{24}$ and Roberts et $\mathrm{al}^{25}$ reported higher incidence of fetal growth restriction in $17.5 \%$ 
and $24.1 \%$ cases of oligohydramnios respectively.

\section{CONCLUSIONS}

Pregnancies complicated by oligohydramnios is associated with increased rate of labour induction and caesarean section mostly for fetal heart rate abnormalities and adverse neonatal outcomes owing to low birth weight, low APGAR score, small for gestational age, birth defects, meconium stained liquor, ICU admission and fetal distress.

\section{ACKNOWLEDGEMENT}

I would like to thank Mr. Dharanidhar Baral and Dr. Rohit Rijal for their help during the statistical analysis of the data and manuscript writing.

\section{DISCLOSURE}

The authors report no conflicts of interest in this work. No violation of human rights and safety.

Findings: nil.

\section{REFERENCES}

1. Jandial C, Gupta S, Sharma S, Gupta M. Perinatal Outcome after Antepartum Diagnosis of Oligohydramnios at or beyond 34 Weeks of Gestation. J K Science. 2007;9(4).

2. Bangal VB, Giri PA, Sali BM. Incidence of oligohydramnios during pregnancy and its effects on maternal and perinatal outcome. JPBMS.2011;12 (05).

3. Elizabeth G. Voxman ST, Wing DA. Low Amniotic Fluid Index as a Predictor of Adverse Perinatal Outcome. Journal of Perinatology. 2002;22:282-285.

4. Gramellini D, Fieni S, Verrotti C, Piantel G, Cavallotti D, Vadora E. Ultrasound evaluation of amniotic fluid volume: method and clinical accuracy. Obstet Gynecol.2004;75:40-4.

5. Phelan JP, Ahn MO, Smith LCDR, Carl V. Amniotic fluid index measurements during pregnancy. J Reprod Med.1987;32:601-4.

6. Garmel SH, Chelmow D, Sha SJ, Roan JT, D'Alton ME. Oligohydramnios and the appropriately grown fetus. Am J Perinatol.1997;14:359-63

7. Conway DL, Adkins WB, Schroeder B, Langer O. Isolated oligohydramnios in the term pregnancy: is it a clinical entity? J Matern Fetal Med.1998;7:197-200.

8. Casey BM, McIntire DD, Bloom SL. Pregnancy outcomes after antepartum diagnosis of oligohydramnios at or beyond 34 weeks' of gestation. Am J Obstet Gynecol.2000; 182:90912 .

9. Chauhan SP, Sanderson M, Hendrix NW. Perinatal outcome and amniotic fluid index in the antepartum and intrapartum periods: A meta-analysis. Am J Obstet Gynecol.1999;181:1473-8.

10. Yussef AA, Abdulla SD, Sayed EH. Superiority of amniotic fluid index over amniotic fluid pocket measuremen for predicting bad fetal outcome. Southern Medical Journal.1993;86:426-9.

11. Zhang J, Troendle J, Meikle S, Klebanoff MA, Rayburn WF. Isolated oligohydramnios is not associated with adverse perinatal outcomes. BJOG.2004;111:220-5

12. Preshit C, Khatri M, Hariharan C. Pregnancy outcome after diagnosis of oligohydramnios at term. Int J Reprod Contracept Obstet Gynecol. 2013;2(1):23-6.

13. Morrisa JM, Thompsona K, Smitheya J, Gaffneya G Cookea I, Chamberlaina P et al. The usefulness of ultrasound assessment of amniotic fluid in predicting adverse outcome in prolonged pregnancy. Br J Obstet Gynaecol. 2003;110:989-
14. Shumway JB, Al-Malt A, Amon E, Cohlan B, Amini S, Abboud M, Winn HN. Impact of oligohydramnios on maternal and perinatal outcomes of spontaneous premature rupture of the membranes at 18-28 weeks. J Matern Fetal Med. 1999;8(1):20-3.

15. Randeniya C. A prosepective study of perinatal outcome in severe oligohydramnios at term. Sri Lanka Journal of Obstetrics and Gynaecology. 1996;18:22-5.

16. Sarno AP, Ahn MO, Brar HS. Intrapartum Doppler velocimetry, amniotic fluid volume and fetal heart rate as prediction of subsequent fetal distress. Is J Obstet Gynecol.1989;161:1508-14.

17. Golan A, Lin G, Evron S. Oligohydramnios: Maternal complications and fetal outcome in 145 cases. Gynecol Obstet Invest. 1994;37:91-5.

18. Desai P, Patel P, Gupta A. Decreased amniotic fluid index in low-risk pregnancy: Any significance? J Obstet Gynecol Ind. 2004;54:464-6

19. Baron C, Morgan MA, Garite TJ. The amniotic fluid volume assessed intrapartum on fetal outcome. American Journal of Obstetrics and Gynecology.1995;173:167-74.

20. Locatelli A, Vergani P, Toso L, Verderio M, Pezzullo JC, Ghidini A. Perinatal outcome associated with oligohydramnios in uncomplicated term pregnancies. Arch Gynecol Obstet. 2004;269:130-3.

21. Ahmad H, Munim S. Isolated Oligohydramnios is not an indicator for adverse perinatal outcome. JPMA. 2009;59:691.

22. Chhabra S, Dargan R, Awaskar R. Oligohydramnios: A potential marker for serious obstetric complications. Journal of Obstetrics and Gynaecology. 2007;27(7):680-3

23. Rotschild A, Ling EW, Puterman ML. Neonatal outcome after prolonged preterm rupture of the membranes. American Journal of Obstetrics and Gynecology. 1990;162:46-52.

24. Shenker L, Reed KL, Anderson CF, Borjon NA. Significance of oligohydramnios complicating pregnancy. American Journal of Obstetrics and Gynecology. 1991;164:1597-600.

25. Roberts D, Nwosu EC, Walkinshaw SA. The fetal outcome in pregnancies with isolated reduced amniotic fluid volume in the third trimester. Journal of Perinatal Medicine.1998;26:390-5. 